\title{
BMJ Open Forecasting and predicting intussusception in children younger than 48 months in Suzhou using a seasonal autoregressive integrated moving average model
}

\author{
Wan-liang Guo, ${ }^{1}$ Jia Geng, ${ }^{2}$ Yang Zhan, ${ }^{1}$ Ya-lan Tan, ${ }^{1}$ Zhang-chun Hu, ${ }^{1}$ Peng Pan, ${ }^{1}$ \\ Mao Sheng, ${ }^{1}$ Jian Wang, ${ }^{3}$ Shun-gen Huang ${ }^{3}$
}

To cite: Guo W, Geng J, Zhan $\mathrm{Y}$, et al. Forecasting and predicting intussusception in children younger than 48 months in Suzhou using a seasonal autoregressive integrated moving average model. BMJ Open 2019;9:e024712. doi:10.1136/ bmjopen-2018-024712

- Prepublication history and additional material for this paper are available online. To view these files, please visit the journal online (http://dx.doi. org/10.1136/bmjopen-2018024712).

W-G and JG contributed equally. MS and S-H contributed equally.

Received 10 June 2018 Revised 9 November 2018 Accepted 13 November 2018

Check for updates

(C) Author(s) (or their employer(s)) 2019. Re-use permitted under CC BY-NC. No commercial re-use. See rights and permissions. Published by BMJ.

'Department of Radiology, Children's Hospital of Soochow University, Suzhou, China ${ }^{2}$ Clinical Laboratory, The 3rd hospital of Yulin, Yulin, China ${ }^{3}$ Department of Pediatric Surgery, Children's Hospital of Soochow University, Suzhou, China

Correspondence to Shun-gen Huang; drhuang01@163.com

\section{ABSTRACT}

Objective The aims of this study were to highlight some epidemiological aspects of intussusception cases younger than 48 months and to develop a forecasting model for the occurrence of intussusception in children younger than 48 months in Suzhou.

Design A retrospective study of intussusception cases that occurred between January 2007 and December 2017.

Setting Retrospective chart reviews of intussusception paediatric patients in a large Children's hospital in SouthEast China were performed.

Participants The hospital records of 13887

intussusception cases in patients younger than 48 months were included in this study.

Interventions The modelling process was conducted using the appropriate module in SPSS V.23.0.

Methods The Box-Jenkins approach was used to fit a seasonal autoregressive integrated moving average (ARIMA) model to the monthly recorded intussusception cases in patients younger than 48 months in Suzhou from 2007 to 2016.

Results Epidemiological analysis revealed that intussusception younger than 48 months was reported continuously throughout the year, with peaks in the late spring and early summer months. The most affected age group was younger than 36 months. The time-series analysis showed that an ARIMA $(1,0,11,1,1)_{12}$ model offered the best fit for surveillance data of intussusception younger than 48 months. This model was used to predict intussusception younger than 48 months for the year 2017, and the fitted data showed considerable agreement with the actual data.

Conclusion ARIMA models are useful for monitoring intussusception in patients younger than 48 months and provide an estimate of the variability to be expected in future cases in Suzhou. The models are helpful for predicting intussusception cases in Suzhou and could be useful for developing early warning systems. They may also play a key role in early detection, timely treatment and prevention of serious complications in cases of intussusception.

\section{Strengths and limitations of this study}

- This was a retrospective study undertaken over an 11-year period in a large hospital in South-East China.

- A seasonal autoregressive integrated moving average model was used for the time-series analysis of intussusception in patients younger than 48 months, as the highest number of intussusception cases in South-East China occur within this age group.

- The models are helpful for predicting intussusception cases in Suzhou and could be useful for developing early warning systems.

- A time series of important influencing factors, which may affect the forecasting accuracy was not obtained.

\section{INTRODUCTION}

Intussusception is the most common cause of intestinal obstruction in the paediatric population, occurring mainly in infants and young children between 3 months and 5 years of age. ${ }^{1-5}$ Previous studies have reported that the incidence of intussusception is between 31 and 100 per 100000 children per year. ${ }^{6-8}$ The clinical manifestations of intussusception in children are usually abdominal masses, colicky abdominal pain, paroxysmal crying and bloody stools. Intussusception is still a major public health concern in China; however, the underlying factors influencing the incidence of intussusception are unclear and effective prevention measures are not available. Previous studies by our group have found both a seasonal pattern and climatic factors associated with the incidence of intussusception. ${ }^{5}$ However, there is no forecasting model for the occurrence of intussusception in children, thus a tool for actively predicting future trends is needed. 
In recent years, linear regression, Poisson regression, Spearman's correlation, non-linear methods and autoregressive time series methods have been used to forecast the incidence of some diseases. ${ }^{9} 10$ The autoregressive integrated moving average (ARIMA) approach is relatively simple and has more predictive power than linear regression, Poisson regression, Spearman's correlation and non-linear methods. In addition, it does not require the user to know the exact influential variables. ${ }^{11}$

In the present study, an ARIMA model was used and applied to time-series data, specifically the incidence of intussusception in patients younger than 48 months in Suzhou, China. To the best of our knowledge, this is the first work to apply ARIMA time-series analysis to fit and forecast the epidemic trend of intussusception in this field.

\section{METHODS}

\section{Study area}

Suzhou is a major transportation hub and economic centre located in South-Eastern China. At the end of 2016, the total population in Suzhou was greater than 10 million. Surveillance data in our hospital showed that more than 1000 intussusception cases had been reported since 2011, with cases in patients younger than 48 months occurring at a rate between 54.5 and 130.8 per 100000 people every year.

\section{Data resources}

The Children's Hospital of Soochow University is the paediatric centre in Suzhou, thus most of the intussusception cases were from this hospital. Some cases from another hospital in Suzhou were included. Once intussusception was detected, though, most of the intussusception cases were transferred to the Children's Hospital of Soochow University for further reduction by air enema or surgery. All the cases were searched using the hospital information system and Picture Archiving and Communication Systems (PACS) imaging workstation in the Children's Hospital of Soochow University. Demographic information (birthplace, gender, birth date), admission and discharge dates were collected. Repeated cases of early recurrent intussusception (12 hours) were excluded from the analysis in this study. The hospital records and radiographs (X-ray) of 13887 intussusception cases in patients younger than 48 months, who came to our hospital between January 2007 and December 2017 were included in this study. The final diagnosis of intussusception was made using ultrasound combined with air enema or surgery. In the time-series analysis, the month served as the unit of time. The daily recorded numbers of intussusception cases in patients younger than 48 months from 2007 to 2017 were aggregated into months, generating 132 data points (monthly). No identification or personal information was revealed.

\section{Modelling method}

The modelling process was conducted using the appropriate module in SPSS V.23.0. Four processes were used to produce the optimal ARIMA model. First, the original series was subjected to square root transformation to induce stationarity. Next, in the identification step, partial autocorrelation function (PACF), and autocorrelation function (ACF) were used to identify the AR and MA components and the stationarity of the square root transformed series. Non-seasonal differencing term (D) term and seasonal D were applied when the series was non-stationary. Third, model parameters were estimated using the least square method. The parameters with statistically significant differences were retained and the others were removed. The goodness of fit of the models was evaluated by diagnostic checking. The one with the lowest normalised Bayesian information criterion (BIC) and the highest coefficient of determination $\left(R^{2}\right)$ was considered the optimal model. The partial autocorrelation and autocorrelation of residuals was diagnosed using the Ljung-Box $(Q)$ test to see whether the series of residuals was white noise. ${ }^{11}{ }^{12} \mathrm{P}<0.05$ was considered statistically significant. Finally, the optimal model was used to predict the expected incidence of intussusception in patients Add younger than 48 moths from January 2017 to December 2017.

\section{Patient and public involvement}

There was no patient or public involvement in this study.

\section{RESULTS}

\section{Surveillance data}

In all, there were 13887 cases of intussusception reported in patients younger than 48 months in our hospital between 2007 and 2017 and $92.5 \%$ underwent successful air enema reductions. The annual number of intussusception cases in patients younger than 48 months was normalised to the total population and expressed as cases per 100000 inhabitants. The annual number of recorded cases of intussusception in patients younger than 48 months between 2007 and 2016 is plotted in figure 1 and table 1 . The highest annual number of recorded intussusception cases in patients younger than 48 months occurred in 2014, with 1577 cases, and the lowest in 2007, with 946 cases. Intussusception cases were recorded throughout the year, with major peaks between April and August (online supplementary figure 1). Cases of intussusception occurred predominantly in boys each year $(63.9 \%) ; 66.8 \%$ of the cases were reported in patients between 4 months and 24 months, and $88 \%$ of the cases occurred in children younger than 36 months of age. The monthly reported incidence of intussusception younger than 48 months exhibited seasonal periodicity, with a major peak occurring from April to July.

\section{Model identification}

The data from January 2007 to December 2016 were used for model development. Before development of the ARIMA model, the raw data from January 2007 to December 2016 were transformed by square root to 


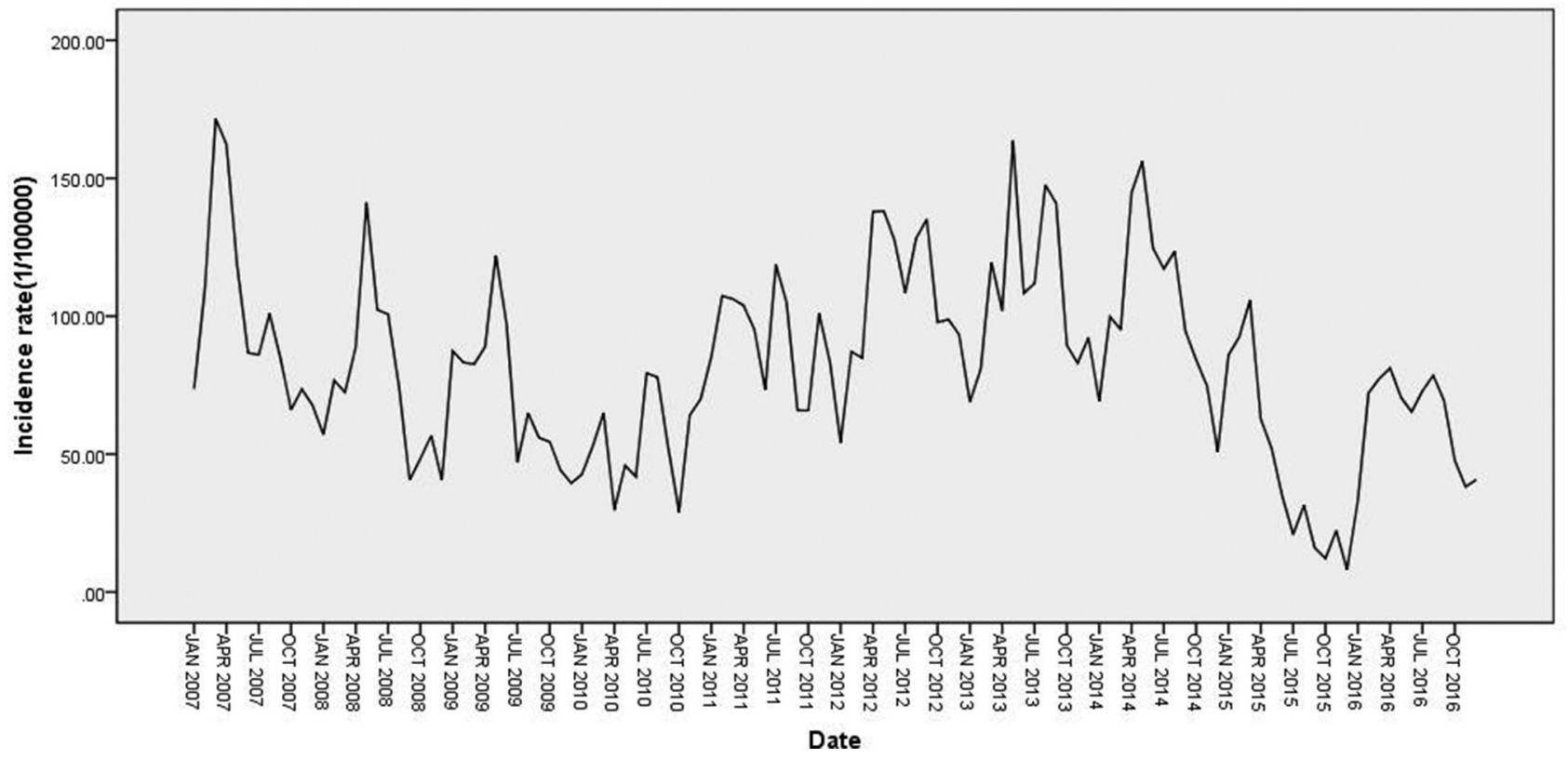

Figure 1 Monthly observed morbidity of intussusception from January 2007 to December 2016 in Suzhou.

induce stationarity. The ACF and PACF plots of the square root transformed data showed a non-stationary variance (figure 2A), confirming the need for D. As shown figure 2B,C the series appeared stationary after one order of seasonal $D$, which suggested that $d$ and $D$ in the seasonal ARIMA $(\mathrm{p}, \mathrm{d}, \mathrm{q})(\mathrm{P}, \mathrm{D}, \mathrm{Q})_{12}$ would be 0 and 1 , respectively.

\section{Model estimation and diagnosis}

Estimates of parameters for possible ARIMA models are shown in table 2. A total of 12 models were found to have statistically significant parameters. According to the goodness-of-fit test statistics, the ARIMA $(1,0,11,1,1)_{12}$ model was confirmed to be the optimal model, which had the highest $\mathrm{R}^{2}(0.697)$ and middle normalised BIC (0.815). The ACF and PACF of the residuals fell within the random CI and showed good fit. The residuals did not show a statistically significant autocorrelation pattern (Ljung-Box test $\mathrm{p}=0.501$ ), indicating that the residual series was white noise, meaning the information was sufficiently extracted (figure 3 ).

\section{Model forecasting}

Data from January 2017 to December 2017 were used to validate the ARIMA $(1,0,1,1,1,1)_{12}$ model and forecasts. The fitted data showed considerable agreement with the actual data, as shown in figure 4 and table 3 . The actual incidence fell within the predicted $95 \%$ confidence limits each time.

\section{DISCUSSION}

Intussusception occurs most frequently in children younger than 48 months and most cases are idiopathic. Among all cases of the intussusception in the present study, about $97.5 \%$ occurred in patients younger than 48 months and about $95 \%$ did not have pathological lead points. These findings are consistent with those of a previous study by Guo and Wong. ${ }^{1314}$ They found pathological lead points in about $0.4 \%-9.9 \%$ of intussusception cases. In the current study, $88 \%$ of the cases occurred in children younger than 36 months of age. One reason

\begin{tabular}{|c|c|c|c|c|c|c|c|c|c|c|c|}
\hline & 2007 & 2008 & 2009 & 2010 & 2011 & 2012 & 2013 & 2014 & 2015 & 2016 & 2017 \\
\hline Number of cases & 946 & 1049 & 1074 & 1105 & 1356 & 1452 & 1567 & 1577 & 1520 & 1206 & 1035 \\
\hline \multicolumn{12}{|l|}{ Gender } \\
\hline Male & 612 & 664 & 670 & 690 & 926 & 886 & 975 & 1024 & 1003 & 773 & 656 \\
\hline Female & 334 & 385 & 404 & 415 & 430 & 566 & 592 & 553 & 517 & 433 & 379 \\
\hline \multicolumn{12}{|l|}{ Age, years } \\
\hline $0 \sim$ & 412 & 413 & 411 & 397 & 481 & 558 & 470 & 505 & 441 & 301 & 280 \\
\hline $1 \sim$ & 281 & 378 & 368 & 372 & 455 & 462 & 550 & 465 & 465 & 444 & 370 \\
\hline $2 \sim$ & 160 & 175 & 201 & 224 & 261 & 289 & 332 & 402 & 376 & 287 & 234 \\
\hline $3 \sim 4$ & 93 & 83 & 94 & 112 & 159 & 143 & 215 & 205 & 238 & 174 & 151 \\
\hline
\end{tabular}


A

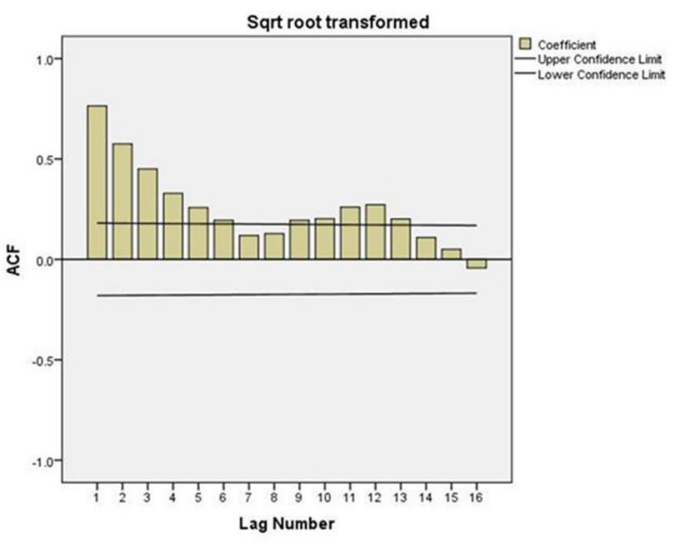

B

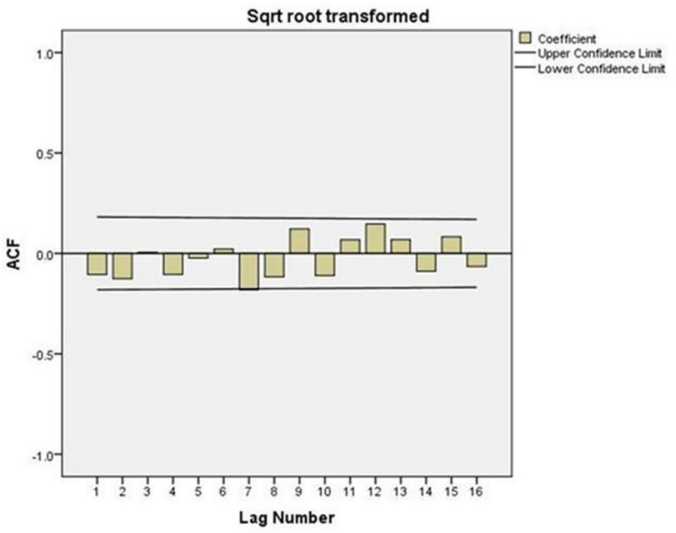

C

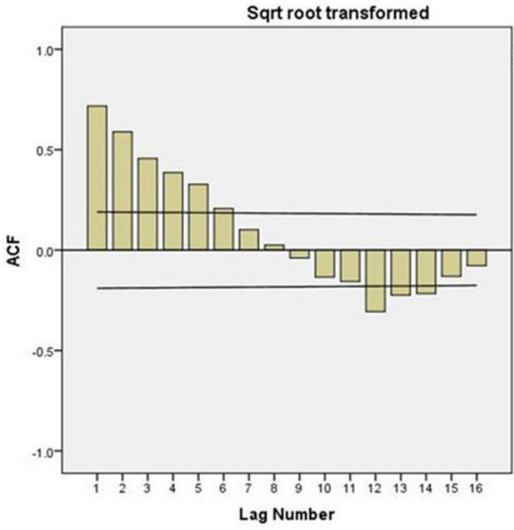

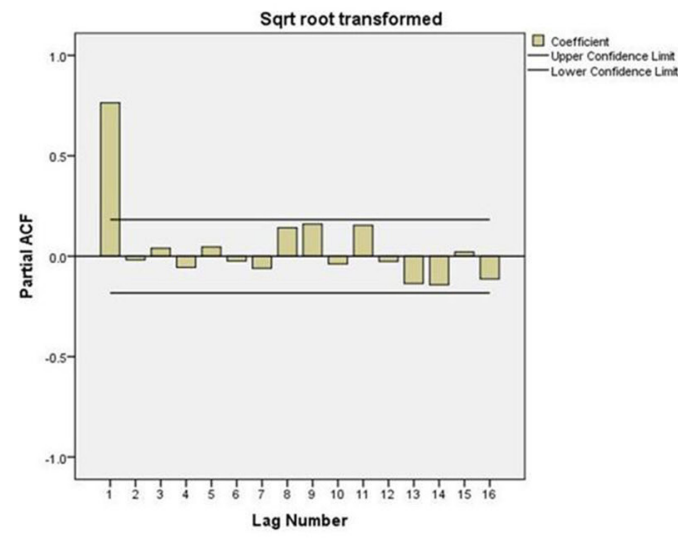
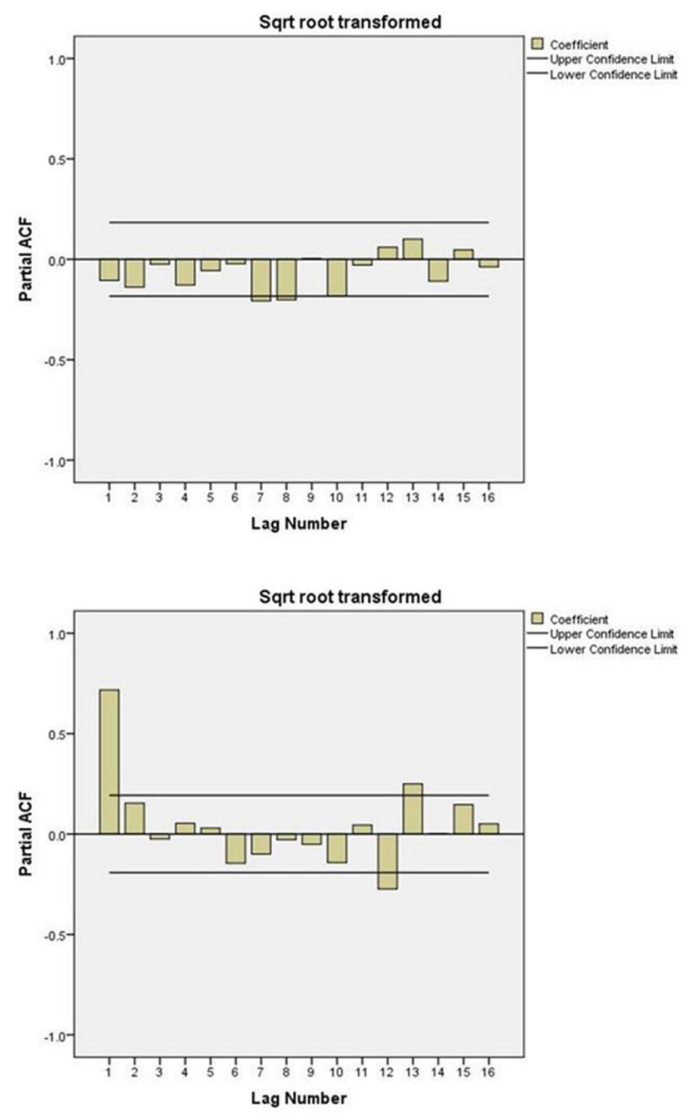

Figure 2 A. Autocorrelation function (ACF) and partial autocorrelation function (PACF) plots of the square root transformed monthly intussusception incidence. (B) ACF and PACF plots after one order of non-seasonal D. (C) ACF and PACF plots after one order of seasonal differencing.

for this may be that the motion of the intestine is more frequent in children younger than 36 months than at other ages. This is consistent with the findings of Chen $e t$ $a l .{ }^{15}$ In the current study, epidemiological analysis showed that intussusception occurred in boys much more often than in girls ( $(63.9 \%$ vs $36.1 \%)$ and Chen et al reported 7541 intussusception cases and also found that male children had a higher incidence rate than female children (61.3 vs 38.7 per 100000 person years, respectively). They also found that the male-to-female incidence rate ratio showed an increasing trend from 1.31 during the first year of life to 2.52 during the ninth year of life. ${ }^{15}$ A similar trend was also reported by Kimia et al (63\% boys vs $37 \%$ girls). ${ }^{16}$

In the 11-year observation period, the number of cases of intussusception increased every year, except in 2016 and 2017. The value normalised to the total population and expressed as cases per 100000 inhabitants increased from 54.5/100 000 to $130.8 / 100000$, which is higher than rates of intussusception reported in most other parts of the world (global median: 74 per 100000 children) $;^{23}$ this means there is a high incidence of intussusception in Suzhou. The current study also found that the monthly reported incidence of intussusception in patients younger 
Table 2 Parameter estimation of autoregressive integrated moving average (ARIMA) models for intussusception forecasting

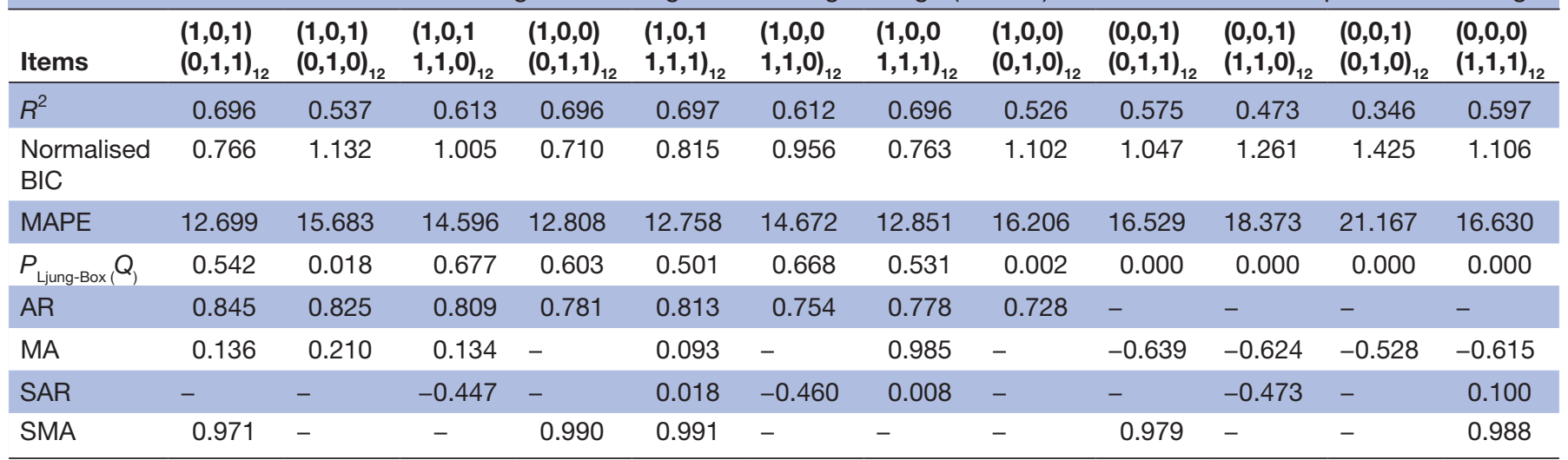

$\mathrm{BIC}$, Bayesian information criterion; MAPE, mean absolute percentage error; $\mathrm{R}^{2}$, coefficient of determination.

than 48 months exhibited seasonal periodicity, with a major peak occurring during the period between April and August, when the weather is warm. This indicates that intussusception occurs mostly during the warm/ hot season in Suzhou. Chen et al retrospectively analysed intussusception cases over 10 years and they found that the mean number of monthly cases was significantly higher during warmer months compared with cooler months. ${ }^{15}$ This is consistent with a previous study done by our group in which the occurrence of intussusception was associated with climatic factors. ${ }^{515}$ It has been suggested that genetic, dietary and environmental factors may play an important role in the variations of intussusception incidence worldwide. $^{7816-18}$

Intussusception is an emergency and any delay in diagnosis or treatment may lead to loss of intestinal viability and may necessitate bowel resection. ${ }^{13}$ There is currently no documented predictive index in the literature for the occurrence of intussusception based on a mathematical model. In a previous study of the effects of climate on

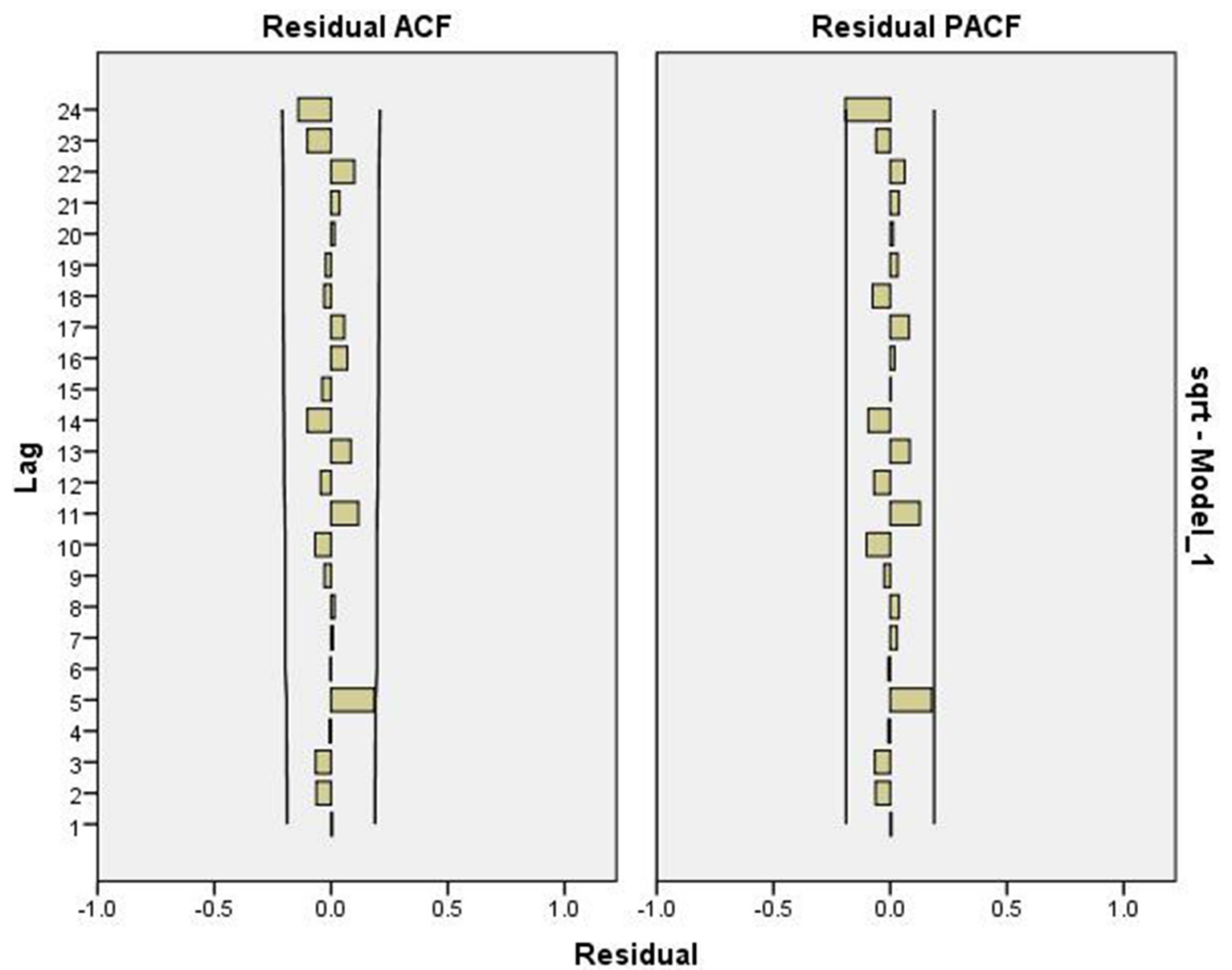

Figure 3 ARIMA $(1,0,11,1,1)_{12}$ model diagnosis. ACF, autocorrelation function; ARIMA, autoregressive integrated moving average; PACF, partial autocorrelation function. 


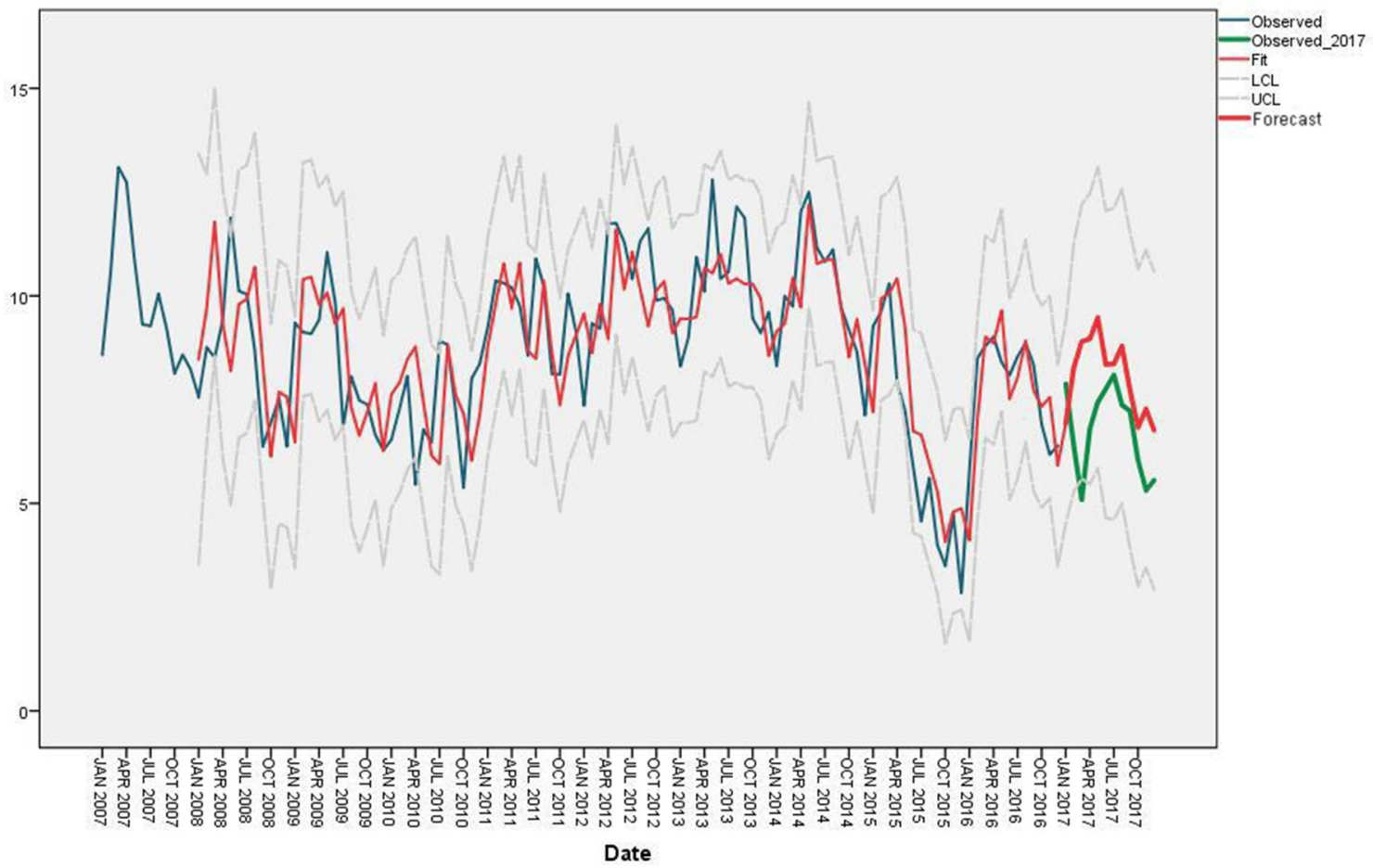

Figure 4 Observations and predictions of the autoregressive integrated moving average (ARIMA) $(1,0,11,1,1)_{12}$ model.

the occurrence of intussusception done by our group, ${ }^{5}$ a seasonal ARIMA model was used for the time-series analysis of intussusception cases in patients younger than 48 months that were collected monthly over a period of 132 months in Suzhou. According to the goodness-of-fit test results, the ARIMA $(1,0,1,1,1,1)_{12}$ model was shown to be useful for monitoring intussusception in patients younger than 48 months and provided estimates of future intussusception cases. The fitted values were

Table 3 Comparison of the actual and predicted incidence of intussusception with autoregressive integrated moving average (ARIMA) $(1,0,11,1,1)_{12}$ model in 2017

\begin{tabular}{lllll}
\hline & $\begin{array}{l}\text { Actual } \\
\text { incidence } \\
\text { (1/100000 } \\
\text { population) }\end{array}$ & $\begin{array}{l}\text { Predicted } \\
\text { incidence } \\
\text { (1/100000 } \\
\text { population) }\end{array}$ & $\begin{array}{l}\mathbf{9 5 \%} \text { Cl of } \\
\text { forecast } \\
\text { (LCL) }\end{array}$ & $\begin{array}{l}\mathbf{9 5 \%} \text { Cl of } \\
\text { forecast } \\
\text { (UCL) }\end{array}$ \\
\hline January & 7.87 & 6.94 & 4.51 & 9.36 \\
\hline February & 6.40 & 8.27 & 5.28 & 11.26 \\
\hline March & 5.09 & 8.90 & 5.29 & 12.21 \\
\hline April & 6.79 & 8.96 & 5.46 & 12.46 \\
\hline May & 7.44 & 9.47 & 5.85 & 13.10 \\
\hline June & 7.76 & 8.35 & 4.64 & 12.05 \\
\hline July & 8.09 & 8.36 & 4.61 & 12.12 \\
\hline August & 7.37 & 8.79 & 5.00 & 12.57 \\
\hline September & 7.23 & 7.73 & 3.92 & 11.54 \\
\hline October & 6.05 & 6.83 & 3.01 & 10.65 \\
\hline November & 5.31 & 7.27 & 3.44 & 11.10 \\
\hline December & 5.56 & 6.76 & 2.93 & 10.59 \\
\hline
\end{tabular}

LCL, low control limit; UCL upper control limit. well matched with the actual observations. It is possible that a cause for intussusception will not be found, and it cannot be prevented as of now. Therefore, effective measures must be taken in order to prevent the complications associated with intussusception. In the current study, the predictions of intussusception incidence in 2017 adequately captured the seasonal pattern observed in previously obtained data. This could be helpful for predicting future development of intussusception in Suzhou and could help the intussusception surveillance system by providing clear ideas for strengthening prevention and control measures and facilitating the initiation of timely treatment, thus helping to prevent complications due to intussusception.

This study has a number of limitations. First, some children in the area may have gone to hospitals in other cities for treatment of intussusception. This may have led to an underestimation of the incidence of intussusception to some extent, even though the hospitals included in this study are the major centres for the treatment of children in Suzhou and would be expected to see the most cases of intussusception. A time series of important influencing factors such as meteorological data or genetic, dietary, environmental and economic factors was not obtained for the modelling, which may have affected the accuracy of forecasting. The floating population is increasing in Suzhou and may lead to fluctuation in the incidences, which cannot be explained and predicted by the ARIMA model at this time; thus further analysis of such data is necessary. 


\section{CONCLUSIONS}

In this study, important baseline information was provided about the current incidence and epidemiological characteristics of intussusception in patients younger than 48 months of age in Suzhou, between 2007 and 2017. This information may be important for evaluating the epidemic of intussusception cases in patients younger than 48 months. In the present study, the ARIMA (1,0,1 $1,1,1)_{12}$ model predicted the incidence of intussusception in patients younger than 48 months in Suzhou. This is an important factor in an early warning system and plays a key role in early detection, timely treatment and prevention of serious complications from intussusception.

Contributors SH and MS designed the study. WG, JG, YT, ZH, PP and JW, collected data. WG, JW, YT, JG and YZ analysed data. WG, SH and MS wrote the manuscript, and all authors read and approved the final version of the manuscript.

Funding This work was supported by Jiangsu Province Health and Family Planning Projects (H201519), Fundamental and Application Research in Health Care of Suzhou (SYS201762).

Competing interests None declared.

Patient consent for publication Not required.

Ethics approval This study was approved by the Institutional Review Board of the Children's Hospital of Soochow University.

Provenance and peer review Not commissioned; externally peer reviewed.

Data sharing statement No additional data are available.

Open access This is an open access article distributed in accordance with the Creative Commons Attribution Non Commercial (CC BY-NC 4.0) license, which permits others to distribute, remix, adapt, build upon this work non-commercially, and license their derivative works on different terms, provided the original work is properly cited, appropriate credit is given, any changes made indicated, and the use is non-commercial. See: http://creativecommons.org/licenses/by-nc/4.0/.

\section{REFERENCES}

1. Parashar UD, Holman RC, Cummings KC, et al. Trends in intussusception-associated hospitalizations and deaths among US infants. Pediatrics 2000;106:1413-21.
2. Huppertz HI, Soriano-Gabarró M, Grimprel E, et al. Intussusception among young children in Europe. Pediatr Infect Dis J 2006;25:S22-9.

3. Jiang J, Jiang B, Parashar U, et al. Childhood intussusception: a literature review. PLoS One 2013;8:e68482.

4. Wong $\mathrm{CW}$, Chan $\mathrm{IH}$, Chung PH, et al. Childhood intussusception: 17year experience at a tertiary referral centre in Hong Kong. Hong Kong Med J 2015;21:518-23.

5. Guo WL, Zhang SF, Li JE, et al. Association of meteorological factors with pediatric intussusception in subtropical china: a 5-year analysis. PLoS One 2014;9:e90521.

6. Bines JE, Patel M, Parashar U. Assessment of postlicensure safety of rotavirus vaccines, with emphasis on intussusception. J Infect Dis 2009;200:S282-90.

7. Tate JE, Simonsen L, Viboud C, et al. Trends in intussusception hospitalizations among US infants, 1993-2004: implications for monitoring the safety of the new rotavirus vaccination program. Pediatrics 2008;121:e1125-32.

8. Justice F, Carlin J, Bines J. Changing epidemiology of intussusception in Australia. J Paediatr Child Health 2005;41:475-8.

9. Sharafi M, Ghaem H, Tabatabaee HR, et al. Forecasting the number of zoonotic cutaneous leishmaniasis cases in south of Fars province, Iran using seasonal ARIMA time series method. Asian Pac J Trop Med 2017;10:79-86.

10. Anwar MY, Lewnard JA, Parikh S, et al. Time series analysis of malaria in Afghanistan: using ARIMA models to predict future trends in incidence. Malar J 2016;15:566.

11. Peng Y, Yu B, Wang P, et al. Application of seasonal auto-regressive integrated moving average model in forecasting the incidence of hand-foot-mouth disease in Wuhan, China. J Huazhong Univ Sci Technolog Med Sci 2017;37:842-8.

12. Gep B, Jenkins GM, Reinsel GC. Time series analysis: forecast and control. 4th edition. Hoboken, New Jersey: John Wiley \& Sons, 2008.

13. Wong CW, Jin S, Chen J, et al. Predictors for bowel resection and the presence of a pathological lead point for operated childhood intussusception: a multi-center study. J Pediatr Surg 2016;51:1998-2000.

14. Guo WL, Hu ZC, Tan YL, et al. Risk factors for recurrent intussusception in children: a retrospective cohort study. BMJ Open 2017;7:e018604.

15. Chen SC, Wang JD, Hsu HY, et al. Epidemiology of childhood intussusception and determinants of recurrence and operation: analysis of national health insurance data between 1998 and 2007 in Taiwan. Pediatr Neonatol 2010;51:285-91.

16. Kimia AA, Williams S, Hadar PN, et al. Positive guaiac and bloody stool are poor predictors of intussusception. Am J Emerg Med 2018;36:931-4.

17. Liu N, Yen C, Huang T, et al. Incidence and epidemiology of intussusception among children under 2 years of age in Chenzhou and Kaifeng, China, 2009-2013. Vaccine 2018;S0264-410X:30206-8.

18. Khumjui C, Doung-ngern P, Sermgew T, et al. Incidence of intussusception among children 0-5 years of age in Thailand, 20012006. Vaccine 2009;27:F116-9. 